\title{
Research on Hedges in English News Reports
}

\author{
Yang Wang ${ }^{1, \text { a }}$
}

${ }^{1}$ Foreign Language College, Jilin Agricultural University, Changchun, Jinlin, China, 130000

${ }^{\mathrm{a} e m a i l,}$

\section{Keywords: Research, Hedges Pragmatic, English News Reports}

\begin{abstract}
The commonly using of Hedges in the news has been paid more and more attention, the use of hedges in English news reports can play the role of accurate information, summarize information, express politeness, self-protection and forming a proper evaluation. Through the definition of hedges and the hedges classification analysis from a pragmatic perspective, combined with the specific English news stories, we explored the language Functions of Hedges and its specific application.
\end{abstract}

\section{Introduction}

In nearly 20 years, English language scholars set off an upsurge of Fuzzy Language. Whether in a formal written expression, or oral verbal communication in everyday life, we often encounter some words or structures which made things vague. G. Lakoff (1972) first proposed the concept of "hedges", that means "making some of the things look vague or make ambiguous things become more clear terms." Hedges are an important part of vague language, it can be used to modify or limit the range of the true reliability and the information provided in the discourse, thereby indicating the extent of its speaker understand or grasp the content, it can be verbal content of subjective inference or speculation, can also provide some objective basis, or personal discourse of content evaluation, and sometimes it can also use a third party to indirectly evaluate for the transmission of information. Under certain contextual factors, Hedges makes verbal expression more scrupulous to achieve better communication purposes.

Hedges is a common linguistic phenomenon which plays a very important role in communication, but it is also a communication strategy with a unique pragmatic functions. In recent years, the research focus moved to the specific genre, such as academic, scientific papers, news, business, diplomacy, advertising and teaching practical language text. But the research results of English news reports Hedges from the perspective of functional grammar is not much and there are a lot of hedges in the news and it has considerable research value.

\section{The Definition of the Fuzzy Hedges}

The American linguist Lakoff first proposed the "Hedges" concept in 1972 and put forward the concept of fuzzy natural language questions. From the point of view of semantics "Hedges", he pointed out that "Hedges" is some words "make things Fuzzy", such as "sort of" "strictly speaking" and so on. "Hedges" as a linguistic term, it originally refers to a member used to modify a noun phrase or predicate subordinate relationship between the expression, usually a word or phrase. Channell thought that "the use of hedges is the speaker or writer stated its true value of the degree of commitment," hedges have the function of helping explain the attitude of speaker or writer. Yule think fuzzy qualifier is "annotated expression is the words to be understood carefully, such as "as far as I know" to provide some information."

The domestic scholars He Ziran translated "Hedges" as "hedges", as defined by Lakoff's "some words to make the hearer not exact information " such as "kind of", "sort of"; and some words that the expression of uncertain meaning or speculate such as "I guess, I think", etc., can be considered hedges. 


\section{The Categories of Hedges}

Hedges are classified into the three main aspects: semantics, syntax and pragmatics in Linguistics. The paper aims to explore the pragmatic function of Hedges in English news reports from the point of view of pragmatic, so we use its classification from the perspective of pragmatic.

According to E. F. Prince and his colleagues J. Frader and C. Bosk (1982), hedges pragmatic can be divided into approx-imators and shields according to its functions. According to the division of H. Price (1975), both types can be further subdivided. The approx-imators type can be divided into adaptors and the rounders according to the degree of fluctuation and scope of the change. The adaptors refer to the original words to make amendments to some extent as a little bit, to some extent, somewhat, more or less, almost, sort of, for example:

He sort of thought this might happen.

Fluctuation range of language (rounders) refers to mafing a definition or limitation to the scope of the changes, such as around, or so, loosely speaking, at least, less than, approximately, something between, and, more than, for example:

In the United States, less than one percent of electricity is produced from wind energy.

The ease of hedges can be classified as direct alleviation language (plausibility) and indirect ease language (attribution shields).. Direct alleviate language (plausibility), refers to the direct expression of the speaker's personal attitudes held by the content of the discourse and subjective guess or infer or hesitation. Discourse in the Central Standing Committee appeared to indicate that the first person is a personal opinion or personal statement, as represented presumed modal particle (such as may, might, etc.) and some expressed hesitation words I think, as far as I can tell, I'm afraid, hard to say, I suppose, I assume, I believe, for example:

Can you explain this to me?

Well. I think you might explain that it's just, this really was a trick.

Indirect ease language (attribution shields) refers to a third- party opinion, often appears in the third person, I speak to exclude, but its purpose is to indirectly indicate the speaker attitude, mood relaxed, as according to, it is said that, as is well-known that, the possibility would be, it has been reported that, presumably, for example: According to Dr. Smith, there was a dramatic response after medication.

\section{The Pragmatic Functions of Hedges in English News Reports}

System functions linguists believe that language is a "meaning potential", the function of language is selecting the language at all levels in the system, namely "option is meaning, meaning is reflected in the form." For the same objective facts, we can use different means of expression from different angles. In the text, the author or the speaker's views and attitudes are reflected through a variety of vocabulary, grammar means. News reports as a mass media, is a special genre, having a specific social function, the language has its own unique style. In pursuit of objective truth as far as possible on the basis of those reports will use some of the vocabulary, grammar means to express themselves, or represent newspapers thoughts, positions and views, and hedges often used in news discourse reflected the author views and positions, which is true and accurate news reporting information requirements are not contradictory, but let language news coverage more accurately, polite, precise, so that readers have more room to think.

Accurate Information. News speak with facts, not vague, ambiguous, neither exaggerate nor reduced. But there is a lot of information in real life and it is less likely to obtain accurate data, but vague expressions make information more reliable, more realistic and thus more convincing. Therefore, the proper use of vagueness in news reports can avoid absolute language to make reports more accurate, truthful and more conducive to improving the quality of news coverage. For example:

More than 30 people were killed Thursday in Lahore, the second largest city in Pakistan, as three teams of militants assaulted two police training centers and a federal investigations building. The dead included 19 police officers and at least11 militants, police officials said. About 33. 4 million 
doses of vaccines have been approved for use as of Saturday, 26 million of which have been dispatched to local medical institutions. The above example used a range change language such as "more than", "at least", "about". Although exact figures are not expressed, but did not affect the reader access to information, people are not concerned with the number itself, but the event itself, concerned about what these people are doing.

Summarizes Information. The fuzzy language is concise, summarized and with the large information content, using fewer words you can make complex facts clear, increase the effect of expression of language, in line with the requirements of simplicity news. The more detailed and comprehensive of news reports, they are more popular by readers of all ages. However, in many cases, it cannot and needs every detail or complex background accurately express it, then by means of fuzzy words can convey information to play a positive role. For example:

The president told thousands of soldiers and relatives gathered outside the headquarters of III Corps./But this much we do know:. No faith justifies these murderous and craven acts No just and loving God looks upon for what he has done, we know that the killer will be met with justice, in this world and the next

At a meeting of finance ministers and central bankers from the Group of 20 leading economies, held over the last weekend, little progress was achieved in sorting out the thorny issue of how rich countries should help poorer nations, except for an agreement to in-crease the research fund.

The above sentence in what he has done, little are some of the more typical, indicates the degree of fuzzy words, with a high degree of generality, vague and succinctly convey information to complete the task of English-language news reports, avoid large space in the news introduced American Army base Fort Hood shootings gunman's actions and the progress of G20 finance ministers and central bank governors meeting on a number of thorny issues to discuss the situation.

Express Politeness. Leech's politeness principle explains the speaker intends to violate the principles of cooperation to implicitly express their real intention is to make words out of courtesy considered decent, it contains six criteria, namely tact maxim, generosity guidelines, endorsed standards, modesty guidelines, consistent with guidelines, compassion guidelines. Hedges on topics related to the true extent and scope of the amendments to the topic, this correction often reflects the principles of decent politeness, humility and consistent criteria; it can also be made directly on the content of the topic subjective guess or make an objective based on the topic for the indirect assessment, which is reflected in the principles of politeness compassion, generosity, and praise and other criteria. The news reports as an indirect way of interpersonal communication, the equivalent of writing conversations, news reports and readers are also the subject of conversation participants, the news reporter also need to pay attention to interpersonal communication means of expression. For example:

It should have been at the end of this week, Bernard Kouchner, the French foreign minister, told France Inter radio, but I don't believe that will happen.

APEC members are reportedly three times more likely to export to others of the group than to a non-member, and two times more likely to import from an-other member than from a nonmember.

News reporter properly used the vague language, the language becomes ambiguous, ensure decent discourse, making the discourse more subtle and tactful, polite, so as not to offend others. Examples of the above with ease direct language "I believe, likely" to express their views to make the author's point of view is not so aggressive.

Self-Protection. In verbal communication, it is inevitable to express their views and positions on an event or phenomenon sometimes. But in order to avoid absolute discourse, extreme, people often use vague language in order to reduce the discourse said to bear the responsibility and risk. News reporter at the time of transmission of information, sometimes for rigorous reporting attitude, or because of the source is not very clear, often use some hedges, the purpose is usually to avoid responsibility after information distortion may incur, so as to achieve self-protection role. For example:

A larmed about the secret payments, Mr. Black cut shor this talks and left Iraq. Soon after returning to the United States, he confronted Erik Prince, the company's chairman and founder, who 
did not dispute that there was a bribery plan, according to a former Black -water executive familiar with the meeting.

Some international media said the clash took place near the Northern Limit Line (NLL), which was by the U. S. -led UN forces at the end of the Korean War, but regarded as invalid by the DPRK.

The above example, by the indirectly using of ease hedges "according to", "somebody said (some international media said", you can help reporter achieve the purpose of reporting this information can also help the main news reports to prevent reports distortion after possible to bear some responsibility, hedges effectively achieve the effect of vicarious liability.

Evaluation Function. It does not use the main news in the news discourse in any manner, just by selecting the appropriate word, words, sentences and grammar in the form of news reporting the facts, in between the lines penetration position to convey their point of view, or by transfer quoted words of others, indirectly, to express their views. Such news often makes news subject's subjective intent imperceptibly penetrate into the audience's thoughts, ideas, thought of the audience, the feelings have different degrees of impact, thereby affecting the audience of the fact that the news judgment. In news reports, evaluation tools capable of expressing author's point of view the attitude of many, such as vocabulary, mood, modality, metaphor. The hedges have accurate information, summarize information, express politeness and self-protection features, but also because of hedges of these features, we can evaluate it as a means to carry out critical reading. Readers cannot passively accept the news, express or hidden in the body language of the news point of view, and to deal with the reported news facts analytical thinking to form their own views and positions later.

\section{Conclusion}

In summary, in news reports, the use of hedges usually have specific pragmatic functions, it is possible to make the news more flexible, to avoid absolute, remain objective, and ultimately more effective, more timely and more accurate transmission of information, so as to achieve the role and function of news reports.

\section{References}

[1] Lakof, f George. Hedges: A Study inMeaning Criteria and the Logic of Fuzzy Concepts [J]. Journal of Philosophical Logic, 1973: 195 -213

[2] Channell J. Vague Language [M] Shanghai: Shanghai Foreign Language Education Press, 2000: 218.

[3] Yule G. Pragmatics[M ]. London: Oxford University Press, 1996: 130.

[4] He Ziran. The hedges and verbal communication [J] Foreign Languages, 2005 (5):27-31.

[5] Chenlin Hua, Li Fuyin. Communication Hedges [J]. Foreign Languages, 2004 (5): 55-58

[6] Wu Tieping. Fuzzy Linguistics [M] Shanghai: Shanghai Foreign Language Education Press, 1999: 73

[7] Huang Guowen. Linguistics research system function integration[J]. Chinese Foreign Languages, 2009 (1): 17-23 